\title{
Numerical Analysis for the Synthesis of Biodiesel Using Spectral Relaxation Method
}

\author{
Z. G. Makukula, ${ }^{1}$ S. S. Motsa, ${ }^{1}$ and S. Shateyi ${ }^{2}$ \\ ${ }^{1}$ School of Mathematics, Statistics and Computer Sciences, University of KwaZulu-Natal, Private Bag X01, Scottsville, \\ Pietermaritzburg 3209, South Africa \\ ${ }^{2}$ Department of Mathematics, University of Venda, Private Bag X5050, Thohoyandou 0950, South Africa
}

Correspondence should be addressed to S. S. Motsa; sandilemotsa@gmail.com

Received 28 March 2013; Accepted 6 November 2013; Published 23 January 2014

Academic Editor: Mufid Abudiab

Copyright (C) 2014 Z. G. Makukula et al. This is an open access article distributed under the Creative Commons Attribution License, which permits unrestricted use, distribution, and reproduction in any medium, provided the original work is properly cited.

\begin{abstract}
Biodiesel is an alternative diesel fuel chemically defined as the mono-alkyl esters of long chain fatty acids derived from vegetable oils or animal fat. It is becoming more attractive as an alternative fuel due to the depleting fossil fuel resources. A mathematical model for the synthesis of biodiesel from vegetable oils and animal fats is presented in this study. Numerical solutions of the model are found using a spectral relaxation method. The method, originally developed for boundary value problems, is an iterative scheme based on the Chebyshev spectral collocation method developed by decoupling systems of equations using Gauss-Seidel type of techniques. The effects of the reaction rate constants and initial concentrations of the reactants on the amount of the final product are being investigated. The accuracy of the numerical results is validated by comparison with known analytical results and numerical results obtained using ode45, an efficient explicit 4th and 5th order Runge-Kutta method used to integrate both linear and nonlinear differential equations.
\end{abstract}

\section{Introduction}

Due to the continuous uncertainty and increasing environmental impact associated with the utilization of petroleumbased diesel fuel, the demands for alternative fuels have increased considerably in recent years [1]. Methyl and ethyl esters derived from vegetable oil or animal fat, known as biodiesel, have good potential as alternative diesel fuel [2]. Biodiesel is synthesized through a chemical process called transesterification. During this chemical process, triglycerides (TG) in vegetable oils or animal fats react with short chain alcohols such as methanol $(\mathrm{MeOH})$ and ethanol in the presence of homogeneous basic catalysts such as sodium hydroxide $(\mathrm{NaOH})$ and potassium hydroxide $(\mathrm{KOH})$ to form fatty acid methyl esters (biodiesel) and glycerin [3, 4].

Biodiesel has many advantages over petroleum-based diesel fuels. It is biodegradable and nontoxic and produce less particles, smoke, and carbon monoxide [2]. It is also renewable and usable in a variety of diesel engines with minimum or no modification necessary $[3,5]$. It burns clean, and do not form engine deposits or generate harmful pollutants which results in a significant reduction of the types of pollutants that contribute to pollution and global warming and releases up to 85\% fewer cancer-causing agents [6-10].

Experiments have been carried out to investigate different aspects in the production of biodiesel [3, 4, 11-15]. In this work, we carry out a numerical study of the transesterification process for the synthesis of biodiesel from vegetable oils. We develop a mathematical model from the experimental works of Santos et al. [2], Burnham et al. [6], and Gunvachai et al. [7], where the reaction equations and reaction rates are given. In this study, the chemical reaction equations and rates are reduced to a set of nonlinear first order differential equations that are solved using a spectral relaxation method. The method decouples nonlinear systems of equations using ideas similar to those of the Gauss-Seidel iterative scheme to give rise to a linear system which is solved sequentially using the Chebyshev spectral method. The method's applicability to initial value problems is also explored in this work. The effects of the reaction rate constants and initial concentrations of 
the reactants on the amount of the final product are being investigated. The accuracy of the numerical results is validated by comparison with known analytical results and numerical results obtained using ode45, an efficient explicit 4 th and 5 th order Runge-Kutta method used to integrate both linear and nonlinear differential equations.

\section{Mathematical Formulation}

Biodiesel (BD) is produced by the transesterification of large, branched triglyceride (TG) molecules into smaller, straight chain molecules with methanol $(\mathrm{MeOH})$ in the presence of an alkali or acid as a (nonreactive) catalyst. The process occurs in three consecutive reactions which in turn produce three by-products, di-glyceride (DG), mono-glyceride (MG), and glycerol (GL) $[2,4,6,7,15,16]$. The thermal transesterification reactions proposed in $[12,13]$ may be characterized as

$$
\begin{gathered}
\mathrm{TG}+\mathrm{MeOH} \stackrel{k_{1}}{\longrightarrow} \mathrm{DG}+\mathrm{R}_{1} \mathrm{COOH}_{3}, \\
\mathrm{DG}+\mathrm{MeOH} \stackrel{k_{2}}{\longrightarrow} \mathrm{MG}+\mathrm{R}_{2} \mathrm{COOH}_{3}, \\
\mathrm{MG}+\mathrm{MeOH} \stackrel{k_{3}}{\longrightarrow} \mathrm{GL}+\mathrm{R}_{3} \mathrm{COOH}_{3},
\end{gathered}
$$

where $k_{1}, k_{2}$, and $k_{3}$ are reaction rate constants. The alternative mathematical model proposed by Kusdiana and Saka [14] ignores the two intermediate reactions and assumes the reaction

$$
\mathrm{TG}+\mathrm{MeOH} \stackrel{k}{\longrightarrow} \mathrm{GL}+\mathrm{RCOOH}_{3} .
$$

In this study we consider the three-stage model defined by (1)-(3). Following $[4,6]$, we assume that there is only one biodiesel product produced in all three reactions so that $R_{1}=R_{2}=R_{3}=R$. In [6], an adaptive Runge-Kutta integrator was used to simulate the set of ODEs that represent the reaction network defined by (1)-(3). In this study, we derive a system of differential equations that model the change in the concentrations of the reactants and the product species with time from (1)-(3) by using the notation,

$$
\begin{array}{cc}
x_{1}=[\mathrm{TG}], & x_{2}=[\mathrm{MeOH}], \\
x_{3}=[\mathrm{DG}], & x_{4}=[\mathrm{BD}], \\
x_{5}=[\mathrm{MG}], & x_{6}=[\mathrm{GL}],
\end{array}
$$

where the square bracket denotes the concentration of the given chemical at time $t$. These equations are

$$
\begin{gathered}
x_{1}^{\prime}(t)=-k_{1} x_{1} x_{2}, \\
x_{2}^{\prime}(t)=-k_{2} x_{1} x_{2}-k_{2} x_{2} x_{3}-k_{3} x_{2} x_{5}, \\
x_{3}^{\prime}(t)=k_{1} x_{1} x_{2}-k_{2} x_{2} x_{3}, \\
x_{4}^{\prime}(t)=k_{1} x_{1} x_{2}+k_{2} x_{2} x_{3}+k_{3} x_{2} x_{5}, \\
x_{5}^{\prime}(t)=k_{2} x_{2} x_{3}-k_{3} x_{2} x_{5}, \\
x_{6}^{\prime}(t)=k_{3} x_{2} x_{5},
\end{gathered}
$$

where the prime denotes the time derivative, subject to the initial conditions

$$
\begin{gathered}
x_{1}(0)=x_{1,0}, \quad x_{2}(0)=x_{2,0}, \\
x_{3}(0)=x_{4}(0)=x_{5}(0)=x_{6}(0)=0 .
\end{gathered}
$$

In (6), the positive terms in the differential equations are those that contribute to an increase in the $x_{i}$ th variable $(i=1, \ldots 6)$, that is to say those terms that contribute positively to the concentration of the different products. The negative terms are those contributing to the decay in the concentration of the different species. Effectively, we start with definite known concentrations of the reacting species with no by-products. As $t \rightarrow \infty$, the concentrations of the reacting species are expected to approach zero and those of the by-products to approach some limiting values, $x_{i, \infty}(i=$ $3,4,5,6)$.

\section{Method of Solution}

In this section, (6) are solved using the spectral relaxation method (SRM). Principally, the method has been developed for similarity boundary layer problems with at least one the essential profiles such as velocity, temperature, or concentration decaying exponentially. The governing systems of equations are decoupled in a manner parallel to the GaussSeidel relaxation method normally used for solving linear algebraic system of equations. Worth noting also is that the method bears some similarities with the Jacobi and GaussSeidel waveform relaxation methods earlier developed by Lelarasmee et al. [17] for solutions of initial value problems (IVPs) in very large-scale electrical networks. However, these methods may result into nonlinear differential equations which require further linearization using appropriate linearization schemes while the SRM gives rise into a sequence of linear differential equations which can be directly solved using standard methods. Spectral methods $[18,19]$ are then used in this work to solve the resulting scheme hence, the name spectral relaxation method. Spectral methods have been chosen in this work because of their well-documented advantages including high accuracy. In developing the sequence of linear equations using the SRM, the following guidelines are used.

(1) The equations have to be arranged in such a way that the equation with the least number of unknowns is placed first on the list.

(2) Variables say $Z_{1}, Z_{2}, Z_{3}, \ldots, Z_{n}$ can be used to assign the ordered equations in [1], such that $Z_{i},(i=$ $1,2,3 \ldots)$ is an unknown function in the $i$ th equation. It is chosen to be the unknown function associated with the highest order derivative of the $i$ th equation.

(3) To generate the iterative scheme, in each equation, only terms linear in $Z_{i}$ are to be evaluated at the current iteration level, $r+1$. All other terms, linear and nonlinear, in the other functions are to be evaluated from the previous iteration, $r$, with an exception from the second equation, where updated solutions for $Z_{i-1}$ 
obtained from the previous $i-1$ equation will be used. Nonlinear terms in $Z_{i}$ are also evaluated from the previous iteration. Terms made up of a product of $Z_{i}$ and its derivatives, the derivative terms are to be evaluated from $r$.

In view of the guidelines above, we develop the iterative scheme for (6) as follows:

$$
\begin{gathered}
\dot{x}_{1, r+1}+k_{1} x_{2, r} x_{1, r+1}=0, \quad x_{1, r+1}(0)=x_{1,0}, \\
\dot{x}_{3, r+1}+k_{2} x_{2, r} x_{3, r+1}=k_{1} x_{1, r+1} x_{2, r}, \quad x_{3, r+1}(0)=0, \\
\dot{x}_{2, r+1}+\left(k_{2} x_{1, r+1}+k_{2} x_{3, r+1}+k_{3} x_{5, r+1}\right) x_{2, r+1}=0, \\
x_{2, r+1}(0)=x_{2,0}, \\
\dot{x}_{5, r+1}+k_{3} x_{2, r+1} x_{5, r+1}=k_{2} x_{2, r+1} x_{3, r+1}, \quad x_{5, r+1}(0)=0, \\
\dot{x}_{4, r+1}=\left(k_{1} x_{1, r+1}+k_{2} x_{3, r+1}+k_{3} x_{5, r+1}\right) x_{2, r+1}, \\
x_{5, r+1}(0)=0, \\
\dot{x}_{6, r+1}=k_{3} x_{2, r+1} x_{5, r+1}, \quad x_{6, r+1}(0)=0 .
\end{gathered}
$$

To solve the iteration schemes (8) we use the Chebyshev spectral collocation method. For brevity, we omit the details of the spectral methods and refer interested readers to [18, 19]. Before applying the spectral method, it is convenient to transform the domain on which the governing equation is defined to the interval $[-1,1]$ on which the spectral method can be implemented. We use the transformation $t=t_{F}(\tau+$ $1) / 2$ to map the interval $\left[0, t_{F}\right]$ to $[-1,1]$, where $t_{F}$ is a finite time. The basic idea behind the spectral collocation method is the introduction of a differentiation matrix $D$ which is used to approximate the derivatives of the unknown variables $x$ at the collocation points as the matrix vector product

$$
\frac{d x}{d t}=\sum_{k=0}^{N} \mathbf{D}_{j k} x\left(\tau_{k}\right)=\mathbf{D X}, \quad j=0,1, \ldots, N
$$

where $N+1$ is the number of grid points known as collocation points, $\mathbf{D}=2 D / t_{F}$, and $\mathbf{X}=\left[x\left(\tau_{0}\right), x\left(\tau_{1}\right), \ldots, x\left(\tau_{N}\right)\right]^{T}$ is the vector function at the collocation points $\tau_{j}$. Applying the Chebyshev spectral collocation method in (8) gives

$$
\begin{array}{cc}
A_{1} \mathbf{x}_{1, r+1}=B_{1}, & x_{1, r+1}\left(\xi_{N}\right)=x_{1,0}, \\
A_{3} \mathbf{x}_{3, r+1}=B_{3}, & x_{3, r+1}\left(\xi_{N}\right)=0, \\
A_{2} \mathbf{x}_{2, r+1}=B_{2}, & x_{2, r+1}\left(\xi_{N}\right)=x_{2,0}, \\
A_{5} \mathbf{x}_{5, r+1}=B_{5}, & x_{5, r+1}\left(\xi_{N}\right)=0, \\
A_{4} \mathbf{x}_{4, \mathrm{r}+1}=B_{4}, & x_{4, r+1}\left(\xi_{N}\right)=0, \\
A_{6} \mathbf{x}_{6, r+1}=B_{6}, & x_{6, r+1}\left(\xi_{N}\right)=0,
\end{array}
$$

where

$$
\begin{gathered}
A_{1}=\mathbf{D}+\operatorname{diag}\left(k_{2} \mathbf{x}_{2, r}\right), \quad B_{1}=\mathbf{0}, \\
A_{3}=\mathbf{D}+\operatorname{diag}\left(k_{1} \mathbf{x}_{2, r}\right), \quad B_{3}=k_{1} \mathbf{x}_{1, r+1} \mathbf{x}_{2, r}, \\
A_{2}=\mathbf{D}+\operatorname{diag}\left(k_{2} \mathbf{x}_{1, r+1}+k_{2} \mathbf{x}_{3, r+1}+k_{3} \mathbf{x}_{5, r}\right), \quad B_{2}=\mathbf{0}, \\
A_{5}=\mathbf{D}+\operatorname{diag}\left(k_{3} \mathbf{x}_{2, r+1}\right), \quad B_{5}=k_{2} \mathbf{x}_{2, r+1} \mathbf{x}_{3, r+1}, \\
A_{4}=\mathbf{D}, \quad B_{4}=\left(k_{1} \mathbf{x}_{1, r+1}+k_{2} \mathbf{x}_{3, r+1}+k_{3} \mathbf{x}_{5, r+1}\right) \mathbf{x}_{2, r+1}, \\
A_{6}=\mathbf{D}, \quad B_{6}=k_{3} \mathbf{x}_{2, r+1} \mathbf{x}_{5, r+1} .
\end{gathered}
$$

From the above equations, diag is a diagonal matrix and $\mathbf{x}_{j}, j=1, \ldots 6$, are the values of the functions $x_{j}$ when evaluated at the collocation points. To start the SRM iterative scheme (20), we use the initial conditions (7) as initial solutions. The scheme is repeated until the solution converges to the numerical solution obtained using the ode 45 .

\section{Results and Discussion}

In this section we present SRM results of the governing equations (6) subject to the initial conditions (7). In experiments, the contents of TG, DG, MG, and GL in samples of reaction product are analyzed periodically using, for example, gas chromatography and the mass fractions of each component calculated based on the concentration of some internal standard $[4,20]$. However in this work we use concentrationtime curves to determine the concentration of each reacting component and products at any given time. We also present results showing the effect of the reaction rate constants on the main product, biodiesel, and the effect of the concentration of the main reactant, methanol, on the concentration of biodiesel produced. The accuracy of the SRM in this work was validated using ode 45, a fourth and fifth order Runge-Kutta scheme whose tolerance level was set to be seven decimal digits $\left(10^{-7}\right)$. A further comparison with similar results in the literature was made. Figures 1,2, 3, and 4 show the conversion of the reaction and yield of biodiesel and the other by-products with reaction time. In all figures, the solid line represents the ode 45 solution while the filled circles, squares, and diamonds represent the SRM solutions. Convergence of the SRM was reached after the 15 th iteration when $N=80$ in all simulations. Figure 1 shows the variation of $[\mathrm{BD}(t)]$ with reaction rate constant $k_{1}$ at different concentrations of $\mathrm{MeOH}$. The concentration of TG was taken to be 0.25 and $k_{2}=0.2$ while $k_{3}=0.13$. The concentration of $\mathrm{BD}$ produced shows to be directly proportional to $k_{1}$ as it increases with increase in $k_{1}$. The concentration of BD produced doubles when $[\mathrm{MeOH}]$ is also doubled. The SRM solutions agree with the ode 45 results.

In Figure 2, the effect of $k_{2}$ is shown to decrease $[\mathrm{BD}(t)]$. In the figure, $k_{1}=0.10, k_{3}=0.13$, and [TG] $=0.25$. The concentration of biodiesel produced in this case is shown to be equal to that of the methanol used. A good agreement between the two solutions is observed. 

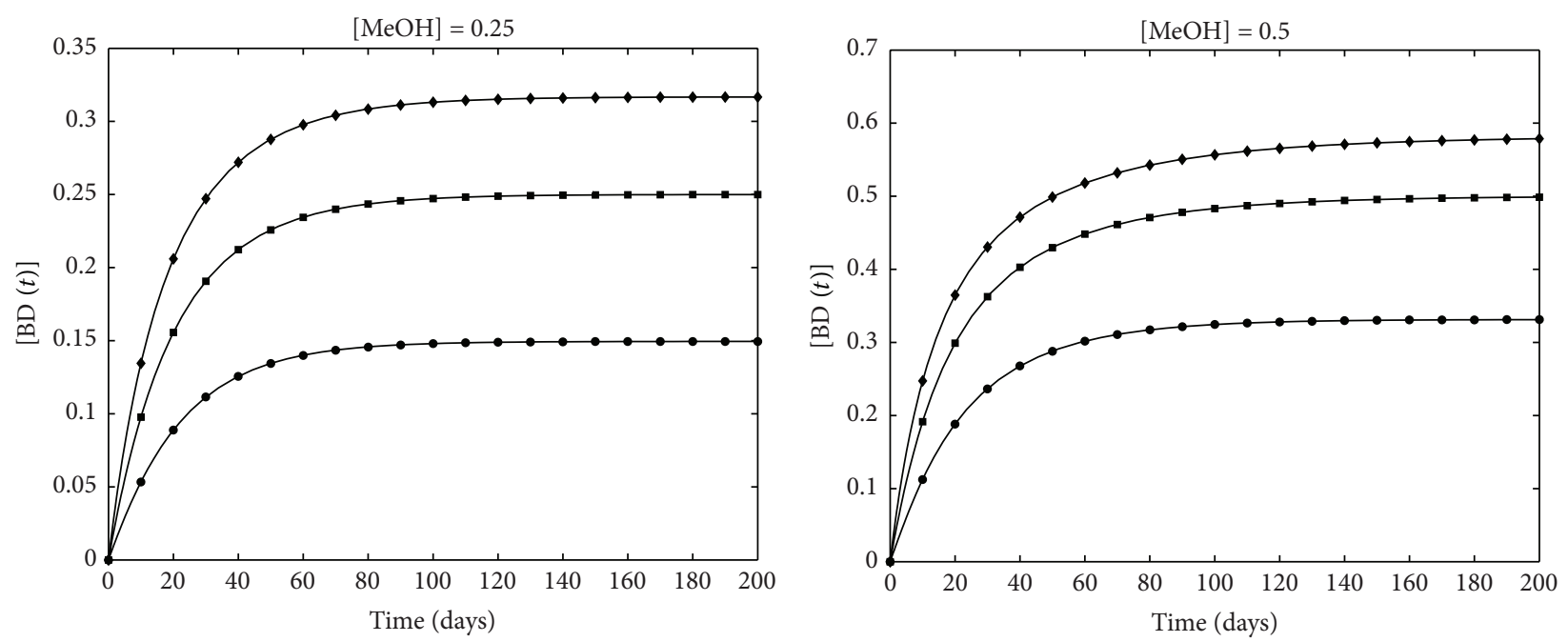

$$
\begin{aligned}
& \text { - } k_{1}=0.1 \\
& \text { - } k_{1}=0.2 \\
& \text { - } k_{1}=0.3
\end{aligned}
$$

$$
\begin{aligned}
& \text { - } k_{1}=0.1 \\
& \text { - } k_{1}=0.2 \\
& \text { - } k_{1}=0.3
\end{aligned}
$$

(a)

(b)

FIGURE 1: Concentration-time curves showing the effect of $k_{1}$ on the concentration of biodiesel produced for different concentrations of $\mathrm{MeOH}$. The solid lines represent ode45 solutions while the figures represent SRM solutions for $k_{2}=0.20, k_{3}=0.13$, $[\mathrm{TG}]=0.25$.

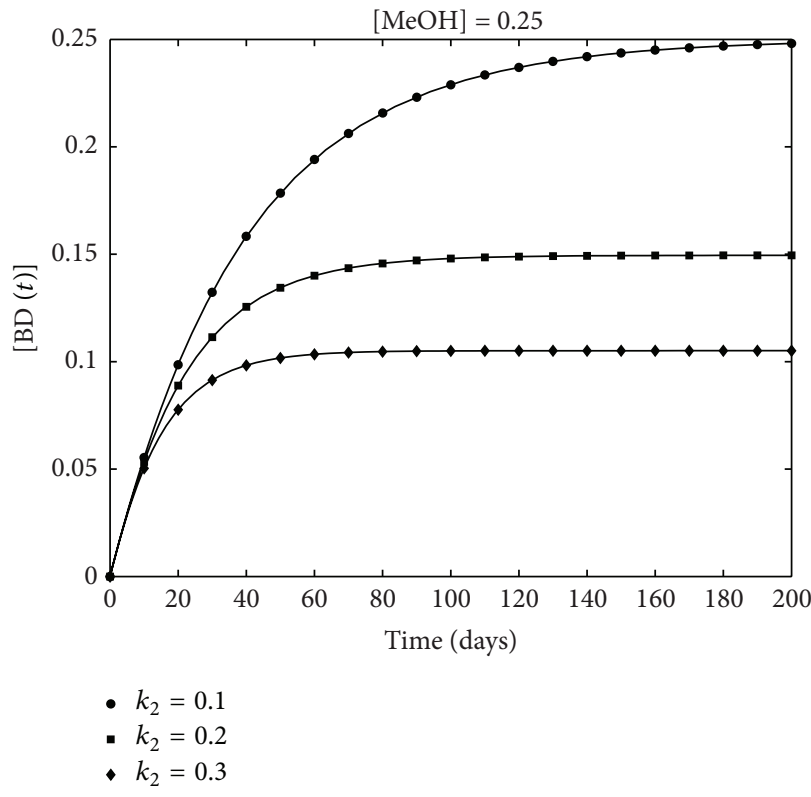

(a)

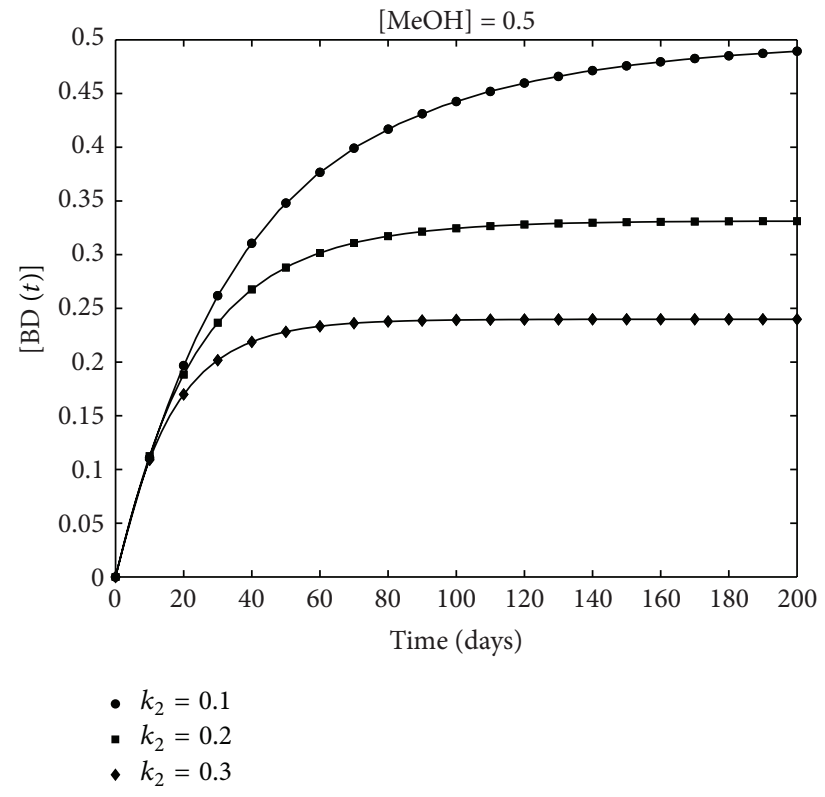

(b)

Figure 2: The effect of $k_{2}$ on the concentration-time curves for biodiesel produced at different concentrations of MeOH. The solid lines represent ode 45 solutions while the figures represent SRM solutions for $k_{1}=0.10, k_{3}=0.13$, [TG] $=0.25$.

The variation of $[\mathrm{BD}(t)]$ with the concentration of the main reactant, $\mathrm{MeOH}$, is shown in Figure 3. Increasing $[\mathrm{MeOH}]$ increases that of $\mathrm{BD}$ produced. In the same figure, it is shown that when $k_{1}=0.10, k_{2}=0.20$, and $k_{3}=0.13$, about $40 \%$ of [TG] gets used up in the reaction, while methanol gets exhausted after about 120 days. The results here are consistent with the analytical results in our earlier study [21]. The two sets of solutions continue to show a very good agreement.
Concentration-time curves for the three by-products are shown in Figure 4. Di-glyceride is produced in stronger concentrations followed by ML and lastly DG.

\section{Conclusion}

A spectral relaxation method has been used successfully in this work to solve a system of differential equations governing 


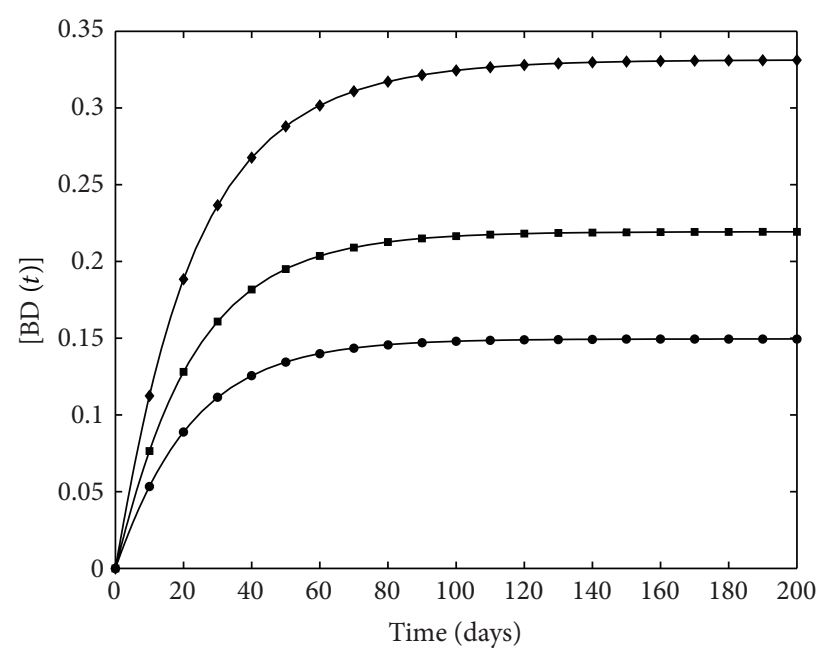

- $[\mathrm{MeOH}]=0.25$

- $[\mathrm{MeOH}]=0.35$

- $[\mathrm{MeOH}]=0.5$

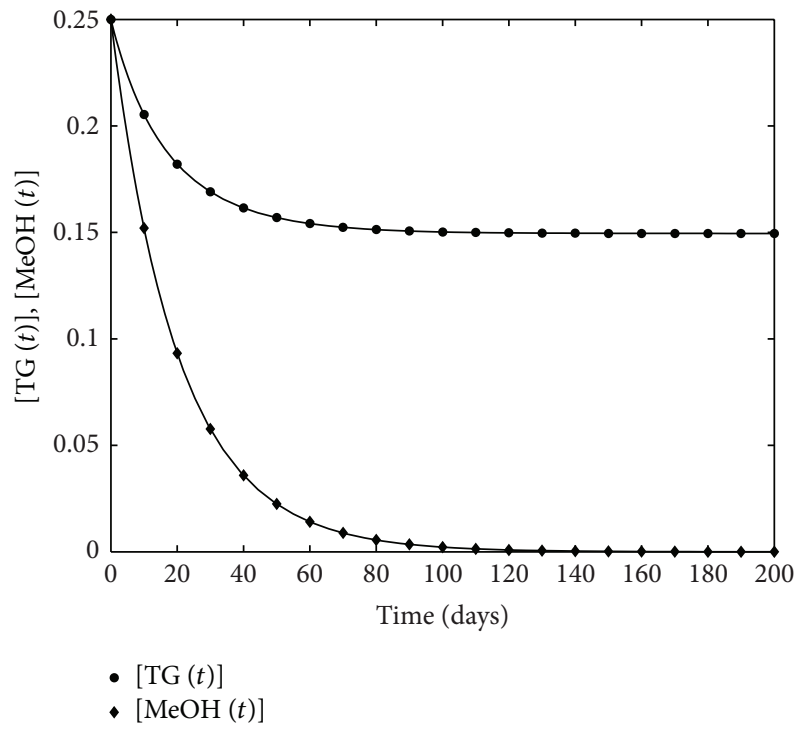

(b)

Figure 3: Concentration-time curves for $\mathrm{BD}$ at different concentrations of $\mathrm{MeOH}$ and that of $\mathrm{TG}$ and $\mathrm{MeOH}$ when $k_{1}=0.10, k_{2}=0.20$, $k_{3}=0.13$. The solid lines represent ode 45 solutions while the figures represent SRM solutions.

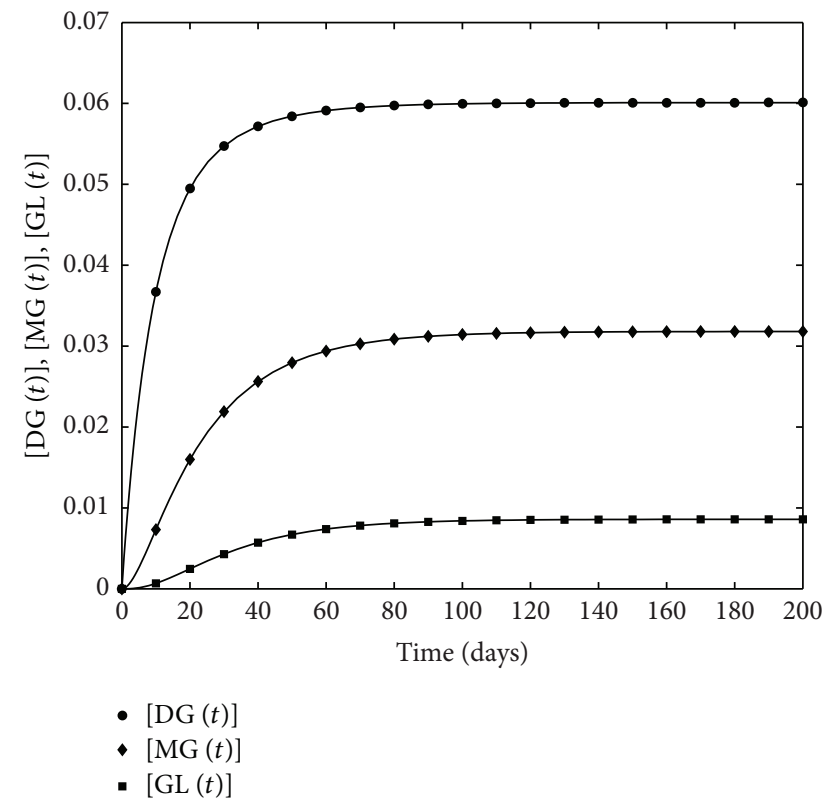

FIGURE 4: The variation of [DG], [MG], and [GL] with time when $[\mathrm{TG}]=[\mathrm{MeOH}]=0.25, k_{1}=0.10, k_{2}=0.20, k_{3}=0.13$. The solid lines denote ode 45 solutions while the figures represent SRM solutions.

the thermal transesterification reactions in the production of biodiesel from vegetable oils. The method proved useful in solving initial value problems of the type in this study. The results were consistent with numerical results obtained using ode45 and those in the works of Sibanda et al. [21]. In the study we investigated the effect of the reaction rate constants and that of the concentration of methanol as the main reactant on the final concentration of biodiesel produced. For optimal results, the study showed that the first reaction rate constant $k_{1}$ should be kept large while the value of $k_{2}$ should be small. The results showed that that is increasing $k_{1}$ increases biodiesel production while increasing $k_{2}$ decreases biodiesel production. The amount of biodiesel produced increases with increase in the initial concentration of methanol used. Methanol is used up in the reaction after sometime. Experimental research is costly compared to theoretical studies. It is however essential to use methods that give accurate results for trustworthy findings. The spectral relaxation method promises to be a viable tool for theoretical studies in the biosciences.

\section{Conflict of Interests}

The authors declare that there is no conflict of interests regarding the publication of this paper.

\section{References}

[1] N. U. Soriano Jr., R. Venditti, and D. S. Argyropoulos, "Biodiesel synthesis via homogeneous Lewis acid-catalyzed transesterification," Fuel, vol. 88, no. 3, pp. 560-565, 2009.

[2] F. F. P. Santos, J. Q. Malveira, M. G. A. Cruz, and F. A. N. Fernandes, "Production of biodiesel by ultrasound assisted esterification of Oreochromis niloticus oil," Fuel, vol. 89, no. 2, pp. 275-279, 2010.

[3] K. Gunvachai, M. G. Hassan, G. Shama, and K. Hellgardt, "A new solubility model to describe biodiesel formation kinetics," Process Safety and Environmental Protection B, vol. 85, no. 5, pp. 383-389, 2007. 
[4] S. Joelianingsih, H. Maeda, S. Hagiwara et al., "Biodiesel fuels from palm oil via the non-catalytic transesterification in a bubble column reactor at atmospheric pressure: a kinetic study," Renewable Energy, vol. 33, no. 7, pp. 1629-1636, 2008.

[5] M. Canakci and J. H. Van Gerpen, "Comparison of engine performance and emissions for petroleum diesel fuel, yellow grease biodiesel, and soybean oil biodiesel," Transactions of the American Society of Agricultural Engineers, vol. 46, no. 4, pp. 937-944, 2003.

[6] S. C. Burnham, D. P. Searson, M. J. Willis, and A. R. Wright, "Inference of chemical reaction networks," Chemical Engineering Science, vol. 63, no. 4, pp. 862-873, 2008.

[7] K. Gunvachai, M. G. Hassan, G. Shama, and K. Hellgardt, "A new solubility model to describe biodiesel formation kinetics," Process Safety and Environmental Protection B, vol. 85, no. 5, pp. 383-389, 2007.

[8] K. Murugesan, T. Ganapathy, and R. P. Gakkhar, "Performance optimization of Jatropha biodiesel engine model using Taguchi approach," Applied Energy, vol. 86, no. 11, pp. 2476-2486, 2009.

[9] P. Pogorevc, B. Kegl, and L. Skerget, "Diesel and biodiesel fuel spray simulations," Energy and Fuels, vol. 22, no. 2, pp. 12661274, 2008.

[10] J. van Gerpen, “Biodiesel processing and production," Fuel Processing Technology, vol. 86, no. 10, pp. 1097-1107, 2005.

[11] D. G. B. Boocock, S. K. Konar, V. Mao, C. Lee, and S. Buligan, "Fast formation of high-purity methyl esters from vegetable oils," JAOCS, Journal of the American Oil Chemists' Society, vol. 75, no. 9, pp. 1167-1172, 1998.

[12] D. Darnoko and M. Cheryan, "Kinetics of palm oil transesterification in a batch reactor," JAOCS, Journal of the American Oil Chemists' Society, vol. 77, no. 12, pp. 1263-1267, 2000.

[13] M. Diasakou, A. Louloudi, and N. Papayannakos, "Kinetics of the non-catalytic transesterification of soybean oil," Fuel, vol. 77, no. 12, pp. 1297-1302, 1998.

[14] D. Kusdiana and S. Saka, "Methyl esterification of free fatty acids of rapeseed oil astreated in supercritical methanol," Journal of Chemical Engineering of Japan, vol. 34, no. 3, pp. 383-387, 2001.

[15] Y. Liu, L. Wang, and Y. Yan, "Biodiesel synthesis combining pre-esterification with alkali catalyzed process from rapeseed oil deodorizer distillate," Fuel Processing Technology, vol. 90, no. 7-8, pp. 857-862, 2009.

[16] M. Slinn and K. Kendall, "Developing the reaction kinetics for a biodiesel reactor," Bioresource Technology, vol. 100, no. 7, pp. 2324-2327, 2009.

[17] E. Lelarasmee, A. E. Ruehli, and A. L. Sangiovanni-Vincentelli, "The waveform relaxation method for time-domain analysis of large scale integrated circuits," IEEE Transactions on ComputerAided Design of Integrated Circuits and Systems, vol. 1, no. 3, pp. 131-145, 1983.

[18] C. Canuto, M. Y. Hussaini, A. Quarteroni, and T. A. Zang, Spectral Methods in Fluid Dynamics, Springer, Berlin, Germany, 1988.

[19] L. N. Trefethen, Spectral Methods in MATLAB, SIAM, Philadelphia, Pa, USA, 2000.

[20] B. Freedman, E. H. Pryde, and W. F. Kwolek, "Thin layer chromatography/flame ionization analysis of transesterified vegetable oil," Journal of the American Oil Chemists' Society, vol. 61, no. 7, pp. 1215-1220, 1984.

[21] P. Sibanda, S. Motsa, and Z. Makukula, "Analysis of the synthesis of biodiesel using the homotopy analysis method," Journal of Advanced Research in Applied Mathematics, vol. 2, no. 3, pp. 23$37,2010$. 


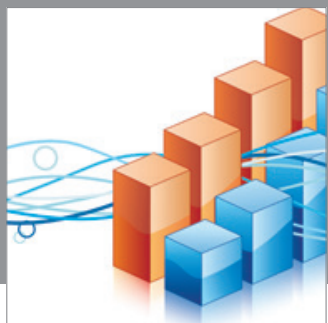

Advances in

Operations Research

mansans

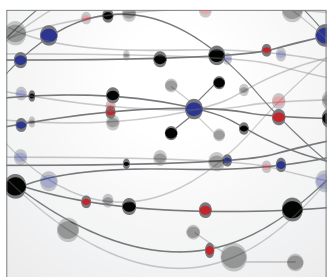

The Scientific World Journal
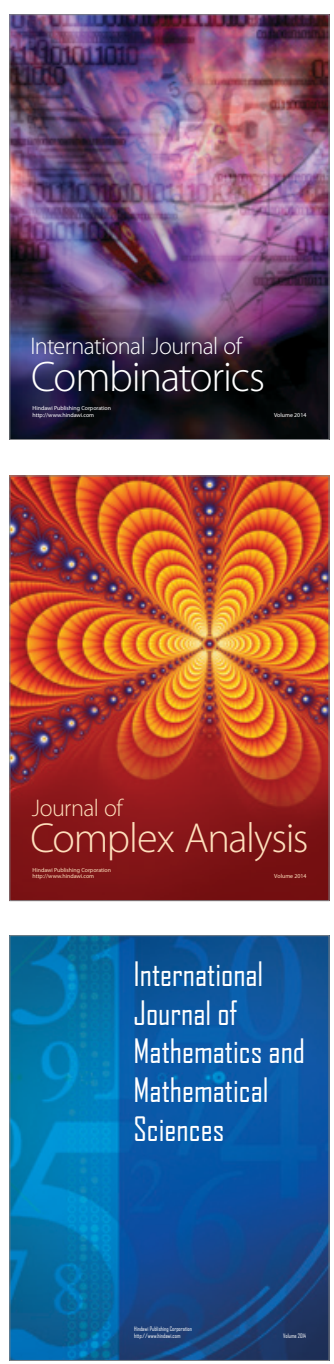
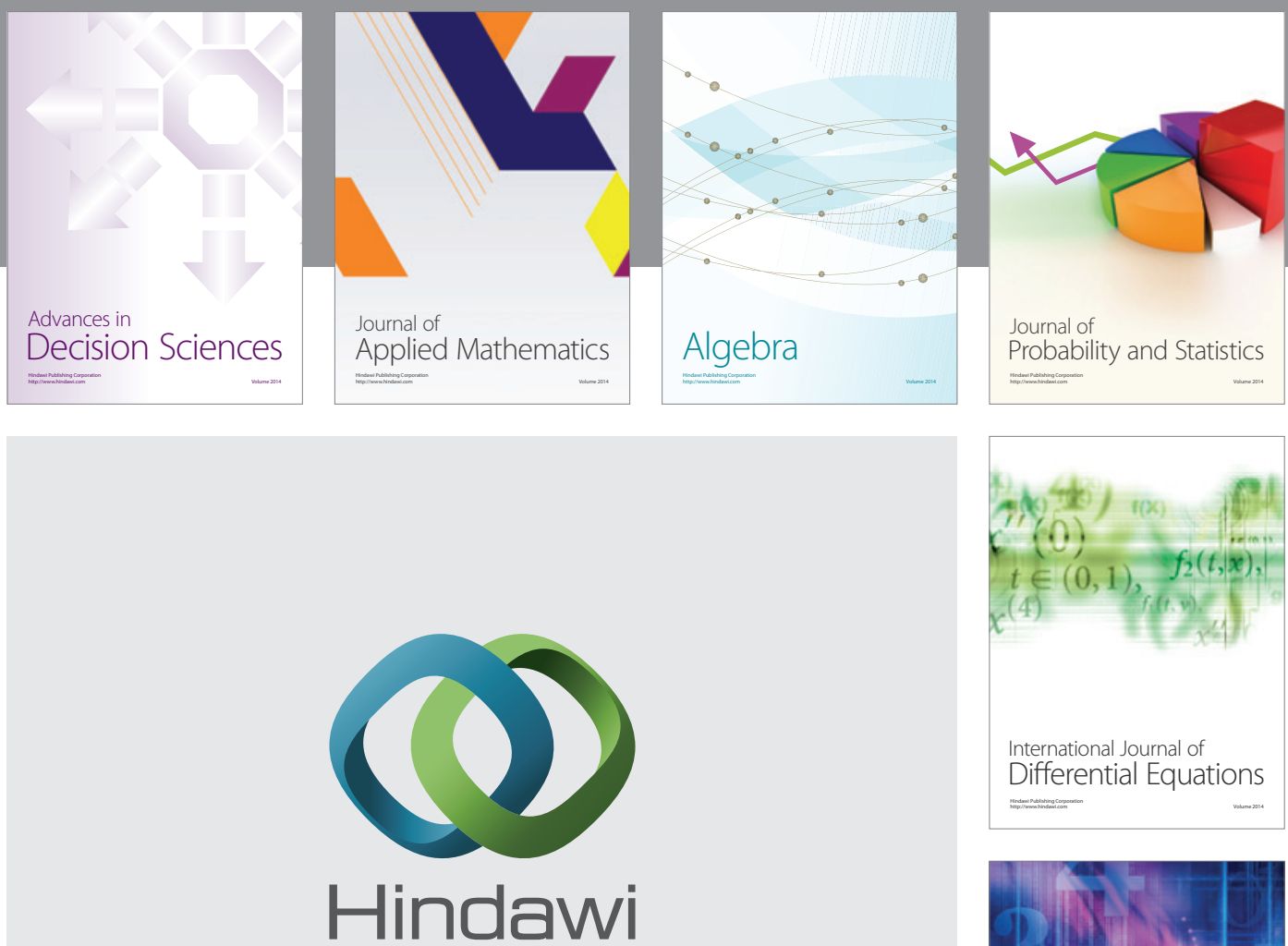

Submit your manuscripts at http://www.hindawi.com
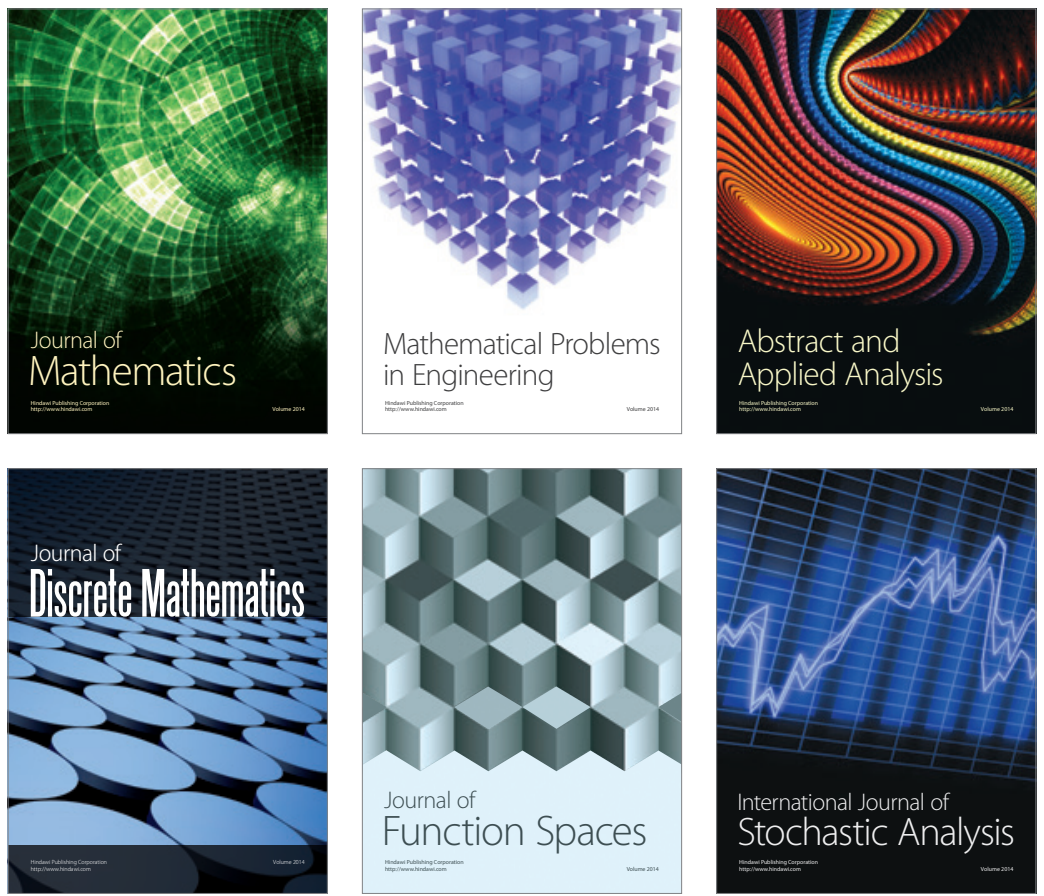

Journal of

Function Spaces

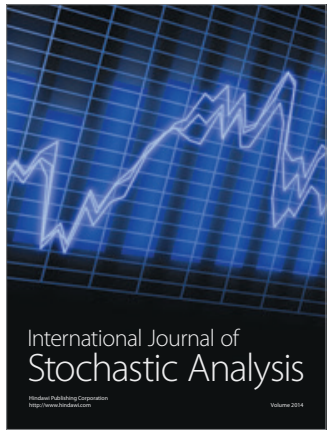

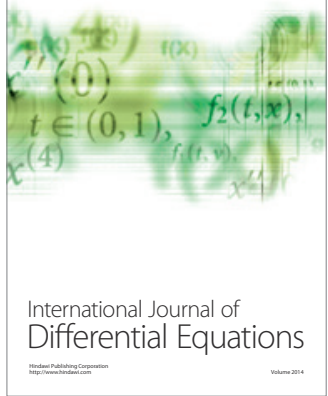
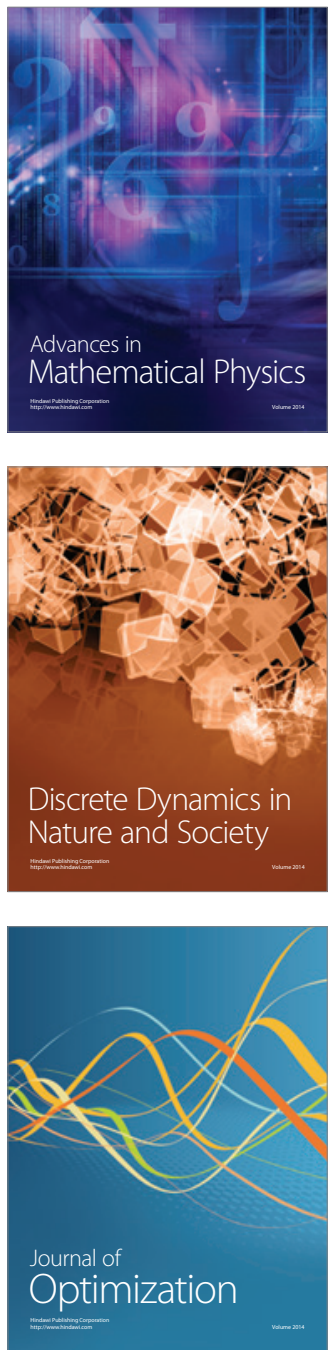